\title{
Prospective Epidemiological Observations on the Course of the Disease in Fibromyalgia Patients Vera Nöller ${ }^{1}$ and Haiko Sprott*2
} Address: ${ }^{1}$ Department of Internal Medicine IV, Friedrich Schiller University, Jena, Germany and ${ }^{2}$ Department of Rheumatology and Institute of
Physical Medicine, University Hospital Zurich, Switzerland

Email: Vera Nöller - haiko.sprott@usz.ch; Haiko Sprott* - haiko.sprott@usz.ch

* Corresponding author

Published: 23 August 2003

Journal of Negative Results in BioMedicine 2003, 2:4

This article is available from: http://www.jnrbm.com/content/2/l/4

(C) 2003 Nöller and Sprott; licensee BioMed Central Ltd. This is an Open Access article: verbatim copying and redistribution of this article are permitted in all media for any purpose, provided this notice is preserved along with the article's original URL.
Received: 15 May 2003

Accepted: 23 August 2003

\begin{abstract}
Objectives: The aim of the study was to carry out a survey in patients with fibromyalgia (FM), to examine their general health status and work incapacity (disability-pension status), and their views on the effectiveness of therapy received, over a two-year observation period.
\end{abstract}

Methods: 48 patients diagnosed with FM, according to the American College of Rheumatology (ACR) criteria, took part in the study. At baseline, and on average two years later, the patients underwent clinical investigation (dolorimetry, laboratory diagnostics, medical history taking) and completed the Fibromyalgia questionnaire (Dettmer and Chrostek [I]).

Results: $27 / 48$ (56\%) patients participated in the two-year follow-up. In general, the patients showed no improvement in their symptoms over the observation period, regardless of the type of therapy they had received. General satisfaction with quality of life improved, as did satisfaction regarding health status and the family situation, although the degree of pain experienced remain unchanged. In comparison with the initial examination, there was no change in either work-capacity or disability-pension status.

Conclusions: The FM patients showed no improvement in pain, despite the many various treatments received over the two-year period. The increase in general satisfaction over the observation period was believed to be the result of patient instruction and education about the disease. To what extent a population of patients with FM would show similar outcomes if they did not receive any instruction/education about their disorder, cannot be ascertained from the present study; and, indeed, the undertaking of a study to investigate this would be ethically questionable. As present, no conclusions can be made regarding the influence of therapy on the primary and secondary costs associated with FM.

\section{Introduction}

Fibromyalgia (FM), or FM syndrome, is a non-articular rheumatic disease with a prevalence of $1-3 \%$ [2-4]. The clinical symptoms include distinctive pain throughout the whole body. Females are more often affected than males [5]. The mean age at disease onset is approximately 42 years and the mean disease duration, 10-12 years [5]. The socio-economic problems associated with the chronic 
Table I: Demographic composition of the patient collective

\begin{tabular}{|c|c|c|}
\hline \multicolumn{3}{|l|}{ Family Status } \\
\hline & Single & $4.2 \%$ \\
\hline & Single living with partner & $2.1 \%$ \\
\hline & Married living with partner & $68.8 \%$ \\
\hline & Married living apart & $4.2 \%$ \\
\hline & Divorced & $4.2 \%$ \\
\hline & Widowed & $2.1 \%$ \\
\hline & No details & $14.4 \%$ \\
\hline \multicolumn{3}{|l|}{ Education } \\
\hline & Primary school & $39.6 \%$ \\
\hline & Secondary school & $25 \%$ \\
\hline & Technical school & $6.3 \%$ \\
\hline & High school graduation & $6.3 \%$ \\
\hline & Other & $10.4 \%$ \\
\hline & No details & $18.7 \%$ \\
\hline \multicolumn{3}{|c|}{ Professional activities } \\
\hline & Working & $20.8 \%$ \\
\hline & 0 - I no longer employed & $6.3 \%$ \\
\hline & I - 5 no longer employed & $25 \%$ \\
\hline & $>10$ no longer employed & $16.7 \%$ \\
\hline & No details & $31.2 \%$ \\
\hline \multicolumn{3}{|c|}{$\begin{array}{l}\text { Severity of physical } \\
\text { activities of those } \\
\text { still employed }\end{array}$} \\
\hline & Multiple layered and heavy & $18.8 \%$ \\
\hline & Multiple layered/middle heavy & $20.8 \%$ \\
\hline & Multiple layered /light & $6.3 \%$ \\
\hline & Shift work/Accord & $2.1 \%$ \\
\hline & Part time & $12.5 \%$ \\
\hline & Missing details & $39.5 \%$ \\
\hline
\end{tabular}

disorder can be considerable, for both the patient and society alike. The persistence of the symptoms makes the prognosis in relation to work capacity extremely difficult. Patients often retire prematurely from the work force usually after long periods of absence from work - such that, over and above the costs associated with treatment itself (direct costs), considerable indirect costs arise in connection with disability pensions and income loss (indirect costs). The latter are difficult to quantify with any certainty, as official records are often inaccessible, but they are estimated to amount to some $15-20 \%$ of the total costs in the field of Rheumatology [6]. This represents $1.2 \%$ of the gross national product of Switzerland [7] and is comparable to the expenditure in other European countries [8]. FM is clearly a problem that deserves more intensive scientific investigation, in relation to both its epidemiology and its socio-medical and economic consequences.

The aim of the present study was to examine the course of the disease, with respect to vegetative and functional symptoms and treatments received over a two-year observation period, in 48 patients with FM.
It was hoped that the findings might assist in identifying potentially successful treatment strategies that would be worthy of closer investigation in further studies, and in providing more information on the likelihood of workretirement due to persistent symptoms.

\section{Methods}

48 patients ( 45 women and 3 men) diagnosed with FM according to the ACR classification criteria [9] were included in the study. Their mean $( \pm$ SEM) age, weight and height were $47.6 \pm 1.9$ years, $76.6 \pm 2.0 \mathrm{~kg}$, and $165 \pm$ $0.01 \mathrm{~cm}$, respectively. The mean duration of the disease (time since appearance of the first symptoms) was $7.2 \pm$ 0.9 years. The demographic data for the study group is summarized in Table 1.

Upon entry to the study (T0) and on average two years later $(\mathrm{T} 1)(2.0 \pm 0.3 \mathrm{y})$, laboratory diagnostics and a detailed rheumatological examination, including dolorimetry, were carried out. The patients completed the Fibromyalgia questionnaire of Dettmer and Chrostek [1], which enquired about marital status, educational background, general state of health, functional and vegetative symptoms, anamnesis regarding pain of the locomotor system, pain behavior, functional disturbances in relation to the time of day and stress and activity. Factors that are intrinsically associated with the disease, such as medication, satisfaction with life (visual analogue scale from $0-10 ; 0=$ very unsatisfied, $10=$ very satisfied $)$, general well-being $(0=$ very bad, $10=$ very good $)$ and the effectiveness of therapeutic measures, were also enquired about. Pain intensity in 24 body parts was rated from $0=$ no pain to $4=$ very severe pain; these scores were summed to give a total pain score for each patient, between 0 and 96 points.

At time-point T1 (2 years later), the patients completed this same questionnaire again, together with a further questionnaire enquiring about treatments, clinical examinations, methods of treatment, inpatient treatment, planned treatment strategies, and the course of the symptoms in the intervening period. Questions about work incapacity and disability payments were included.

\section{Results \\ Dolorimetry, pain and functional/vegetative symptoms at time point TO}

The dolorimetric examination revealed a mean $( \pm$ SEM) number of positive tender points per patient of $16.6 \pm 0.5$. The mean pain threshold for these was $1.4 \pm 0.04 \mathrm{kp}$. The pain score was $53.3 \pm 2.8$. Table 2 shows the frequency of functional and vegetative symptoms. The difference of "moderate" and "high" has pathological meaning. 
Table 2: Frequency of occurrence of functional and vegetative symptoms in percent of the degree of pronouncement (ordered alphabetically). 42 patients answered the questions.

\begin{tabular}{|c|c|c|c|c|}
\hline Symptom & None & Slight & Moderate & Strong \\
\hline Allergy & 50.0 & 8.3 & 14.6 & 14.6 \\
\hline Breathlessness & 41.7 & 14.6 & 27.1 & 4.2 \\
\hline Stomach complaints & 41.7 & 14.6 & 20.8 & 10.4 \\
\hline Complaints urinating & 60.4 & 16.7 & 4.2 & 6.3 \\
\hline Diarrhoea & 68.8 & 6.3 & 10.4 & 2.1 \\
\hline Trouble sleeping through & 12.5 & 10.4 & 27.1 & 37.5 \\
\hline Trouble going to sleep & 12.5 & 12.5 & 31.3 & 31.3 \\
\hline Disturbances of the senses of the upper extremity & 22.9 & 12.5 & 35.4 & 16.7 \\
\hline Disturbances of the senses of the lower extremity & 18.8 & 20.8 & 31.3 & 16.7 \\
\hline Heart problems & 25.0 & 12.5 & 33.3 & 16.7 \\
\hline Cold hands or feet & 14.6 & 14.6 & 33.3 & 25.0 \\
\hline Lump in the throat feeling & 35.4 & 12.5 & 25.0 & 14.6 \\
\hline Headaches & 12.5 & 18.8 & 16.7 & 39.6 \\
\hline Circulatory disturbances & 14.6 & 16.7 & 35.4 & 20.8 \\
\hline Morning Stiffness & 12.5 & 2.1 & 39.6 & 33.3 \\
\hline Fatigue & 12.5 & 10.4 & 39.6 & 25.0 \\
\hline Tendency to sweat & 20.8 & 14.6 & 27.1 & 25.0 \\
\hline Menstruation pain & 62.5 & 4.2 & 6.3 & 14.6 \\
\hline Swallowing problems & 56.3 & 12.5 & 16.7 & 2.1 \\
\hline Swelling of the upper extremity & 31.3 & 6.3 & 37.5 & 12.5 \\
\hline Swelling of the lower extremity & 27.1 & 12.5 & 29.2 & 18.8 \\
\hline Indigestion & 54.2 & 8.3 & 14.6 & 10.4 \\
\hline Dry mouth & 29.2 & 14.6 & 22.9 & 20.8 \\
\hline Irregular menstruation & 77.1 & 2.1 & 4.2 & 4.2 \\
\hline Reduced capability & 2.1 & 2.1 & 33.3 & 50.0 \\
\hline Constipation & 60.4 & 10.4 & 10.4 & 6.3 \\
\hline Feeling full & 33.3 & 6.3 & 25.0 & 22.9 \\
\hline Trembling hands & 43.8 & 14.6 & 25.0 & 4.2 \\
\hline
\end{tabular}

The differences of $100 \%$ correspond to the missing details.

The following symptoms appeared in either a moderate or severe form in more than $50 \%$ of the patients: disturbances in getting to sleep and insomnia, sensory disturbances of the upper extremities, heat complaints, cold acres, headaches, orthostatic reactions, morning stiffness, fatigue, hyperhydrosis, the feeling of swollenness in the extremities, and diminished overall capabilities (83.3\%!). The results of the visual analogue scale ratings from $0-10$ provide more specific information about the patients' pain-induced functional limitations (Table 3):

\section{Pattern of pain at time point TO}

In their pain history $4.2 \%$ of the patients reported a dramatic onset of pain over a short period of time, 16.7\% reported a slow progression of pain over a longer period of time, 54.2\% reported flare-ups of pain over and above an ongoing pain problem and $10.4 \%$ reported flare-ups with pain-free intervals. $14.5 \%$ of the patients gave no information about their pain pattern.
Factors influencing the pain and activity factors at TO

$77.1 \%$ of the patients declared no diurnal changes in their pain, though a dependency on other factors (physical, psychological, weather) was reported $(68.6 \%$ of the patients). $12.5 \%$ of the patients carried out less than an hour of physical activity per day, $12.5 \% 1-2$ hours per day and $10.4 \%$ more than 2 hours a day. $52.1 \%$ of the patients carried out no sport at all.

$41.7 \%$ of the patients answered the question about the possible cause of their symptoms with "don't know". $14.6 \%$ suspected that occupational factors might be responsible, $4.2 \%$ family burdens, $4.2 \%$ previous operative procedures, and $2.1 \%$ previous infection. $33.3 \%$ of the patients saw no connection between the course of the disease and any of these possible burdens (occupational burdens infections, and operations).

At time point T0, $68.8 \%$ of the patients were being treated with medication for pain and rheumatic complaints. $45.8 \%$ of the whole group felt that the medication did not 
Table 3: Visual Analogue Scale from 0 to 10. Both extremes are noted under the heading.

\begin{tabular}{|c|c|}
\hline & Medium \pm SEM \\
\hline $\begin{array}{l}\text { General state of health assessment } \\
\text { (very bad - very good) }\end{array}$ & $2.8 \pm 0.3$ \\
\hline $\begin{array}{l}\text { Assessment of lack of motivation } \\
\text { (very frequent - more or less never) }\end{array}$ & $4.2 \pm 0.4$ \\
\hline $\begin{array}{l}\text { Contentment with the work situation } \\
\text { (very dissatisfied - very satisfied) }\end{array}$ & $4.1 \pm 0.6$ \\
\hline $\begin{array}{l}\text { Obstruction through state of health } \\
\text { (very much - absolutely not) }\end{array}$ & $1.9 \pm 0.2$ \\
\hline $\begin{array}{l}\text { Worry because of state of health } \\
\text { (very much - absolutely not) }\end{array}$ & $2.0 \pm 0.3$ \\
\hline $\begin{array}{l}\text { Contentment with relationship with friends etc. } \\
\text { (very dissatisfied - very satisfied) }\end{array}$ & $7.1 \pm 0.4$ \\
\hline $\begin{array}{l}\text { Contentment with family situation } \\
\text { (very dissatisfied - very satisfied) }\end{array}$ & $7.5 \pm 0.4$ \\
\hline $\begin{array}{l}\text { Contentment with financial situation } \\
\text { (very dissatisfied - very satisfied) }\end{array}$ & $5.2 \pm 0.4$ \\
\hline $\begin{array}{l}\text { Contentment with leisure time } \\
\text { (very dissatisfied - very satisfied) }\end{array}$ & $6.7 \pm 0.4$ \\
\hline $\begin{array}{l}\text { General contentment } \\
\text { (very dissatisfied - very satisfied) }\end{array}$ & $4.3 \pm 0.4$ \\
\hline $\begin{array}{l}\text { Worry about health } \\
\text { (very frequent }- \text { more or less never) }\end{array}$ & $1.6 \pm 0.3$ \\
\hline $\begin{array}{l}\text { Depression } \\
\text { (very frequent - more or less never) }\end{array}$ & $4.3 \pm 0.5$ \\
\hline $\begin{array}{l}\text { Strength of feeling of pain } \\
\text { (Very strong - hardly at all) }\end{array}$ & $2.0 \pm 0.2$ \\
\hline $\begin{array}{l}\text { Restlessness and tenseness } \\
\text { (very frequent }- \text { more or less never) }\end{array}$ & $2.5 \pm 0.4$ \\
\hline $\begin{array}{l}\text { Frequency of full exhaustion } \\
\text { (very frequent - more or less never) }\end{array}$ & $2.3 \pm 0.4$ \\
\hline $\begin{array}{l}\text { Contentment with living situation } \\
\text { (very dissatisfied - very satisfied) }\end{array}$ & $7.4 \pm 0.4$ \\
\hline
\end{tabular}

relieve their symptoms, whilst $37.5 \%$ reported a relief in pain. Other therapy forms (especially active and passive physical modalities) had been tried by $85.4 \%$ of the patients without satisfactory long-term effects. $29.2 \%$ of the patients had previously been treated on an inpatient basis in connection with their diagnosis of FM (during investigation of their symptoms). $60.4 \%$ of the patients had previously undergone surgery for disorders of the locomotor system (and also of the gynecological and abdominal systems), without any satisfactory effect.

\section{Patients' history between time points TO and TI} Change in the social environment

$31.9 \%$ of the patients reported no change in their social environment between T0 and T1. 8.5\% reported changes in their workplace, and $6.4 \%$ changes in their leisure activities.

\section{Planning of further treatment strategies}

There were no further treatment measures planned by the treating therapist for $25.5 \%$ of the patients. $55.3 \%$ of the patients were being treated pragmatically, e.g. symptomoriented, in various ways, and $2.1 \%$ were being treated with acupuncture. $53.2 \%$ of the patients had consulted more than one doctor. Only $4.3 \%$ had been treated by their family doctor. $44.7 \%$ of the patients reported that they had suffered severely from insomnia. $51.1 \%$ of the patients had a daily schedule with regular times for getting up, relaxing, eating, leisure activities and sleeping. $44.7 \%$ of the patients declared that pain of the locomotor system was their main complaint.

\section{Pension application and retirement}

By time-point T1, 19.1\% ( $\mathrm{n}=9)$ of the patients had applied for a disability pension, which was one patient more than at time-point T0.

\section{In-patient treatment}

$27.7 \%$ of the patients had had no intermediary inpatient treatment for their FM symptoms in the observation period; $23.4 \%$ had had less than 2 inpatient treatments and $6.4 \%$ more than 2 inpatient treatments.

\section{Further examinations}

$36.2 \%$ of the patients had undergone further diagnostic investigations over the observation period; $10.6 \%$ had had an X-ray examination. Only $6.4 \%$ had undergone further diagnostic examinations due to their existing symptoms.

\section{Examination at time point TI (2 Years \pm 3 Months)}

27 patients (56\%) took part in the examination at T1. The significant changes observed between $\mathrm{T} 0$ and $\mathrm{T} 1$ are shown in Table 4. No changes were recorded in the variables: disturbances getting to sleep, insomnia, tender points, blood sedimentation rate, influence of medication, difficulties passing water, work capacity, drive, morning stiffness, influence of therapy measures (especially medication), circulation disturbances, headaches, lump in the throat feeling, heart complaints, body weight, sensory disturbances of the lower extremities, sensory disturbances of the upper extremities, leisure time, financial status, marital status, sense of swollenness of the upper extremities, pain, influence of other factors on pain, swallowing problems, pain pattern, menstruation pain, depression, tendency to sweat, and diurnal changes in symptoms.

\section{Discussion}

Between baseline and follow-up, significant improvements were recorded in all the vegetative symptoms, with the exception of "dry mouth" (Table 4). The patients at time point $\mathrm{T} 1$ who had an unchanged number of tender 
Table 4: Significantly changed parameters/symptoms (appearing alphabetically) between T0 and TI.

\begin{tabular}{llll}
\hline Symptom/Parameter & Medium \pm SEM Time point TO & Medium \pm SEM Time point TI & Significance $p$ \\
\hline Allergies & $0.93 \pm 0.18$ & $1.56 \pm 0.25$ & 0.004 \\
General condition & $3.0 \pm 0.276$ & $4.44 \pm 0.44$ & 0.001 \\
Breathlessness & $0.93 \pm 0.15$ & $1.63 \pm 0.22$ & 0.004 \\
Stomach problems & $1.0 \pm 0.17$ & $1.67 \pm 0.24$ & 0.019 \\
Diarrhoea & $0.38 \pm 0.12$ & $0.85 \pm 0.21$ & 0.022 \\
Family situation & $7.5 \pm 0.387$ & $8.27 \pm 0.507$ & 0.02 \\
Health & $1.65 \pm 0.314$ & $3.25 \pm 0.57$ & 0.044 \\
Cold acres & $1.79 \pm 0.16$ & $2.3 \pm 0.18$ & 0.006 \\
Fatigue & $1.88 \pm 0.15$ & $2.37 \pm 0.16$ & 0.044 \\
Surgery & $2.21 \pm 0.07$ & $0.77 \pm 0.3$ & 0.02 \\
Pain Score & $53.29 \pm 2.78$ & $57.39 \pm 3.96$ & 0.006 \\
Swelling of the lower extremities & $1.45 \pm 0.18$ & $1.78 \pm 0.25$ & 0.027 \\
Sports & $0.79 \pm 0.17$ & $1.48 \pm 0.22$ & 0.024 \\
Dry mouth & $1.4 \pm 0.18$ & $1.67 \pm 0.23$ & 0.048 \\
Constipation & $0.57 \pm 0.15$ & $0.81 \pm 0.23$ & 0.014 \\
Trembling hands & $0.88 \pm 0.15$ & $1.19 \pm 0.24$ & 0.008 \\
\hline
\end{tabular}

points (dolorimetry) registered a significantly higher pain score. None of the therapeutic measures that had been implemented (medicinal, physiotherapy, psychotherapy) had resulted in any improvement. Despite this, the selfrated general state of health showed a significant improvement $(\mathrm{p}=0.001)$.

Generally, it may be concluded that the current therapies implemented for the treatment of FM appear to be ineffective, and this clearly results in a frustrating situation for both the patient and therapist alike. There is currently no clear understanding of the pathogenesis of FM and, as such, poly-pragmatic therapeutic recommendations [10] remain the only recommended treatment option. Over the two-year period of observation, our patients showed no fundamental changes in the parameters investigated. Thus, instruction and information about the disease might be the only relevant tools to stabilize the patient's general satisfaction with the situation, even if the pain experienced does not change. These "small" successes should be seen as sufficient grounds for implementing interdisciplinary approach in FM, without undertaking extensive, unfounded diagnostic and/or therapeutic interventions. The reported increase in dry-mouth is primarily attributable to therapy with anti-depressive medication (in particular tricyclic anti-depressants). Over the study duration, there were no significant changes in the patients' work capacity or disability-pension status. To what extent the patients would have shown a different course of disease without any therapeutic intervention, or care from healthcare professionals, cannot be ascertained from the present study; and, indeed, such studies are difficult to implement, for ethical reasons.
In conclusion, independent of the applied therapeutic management of the disease, there was neither a clinical relevant benefit nor a worsening of symptoms in our investigated group of patients.

\section{Acknowledgement}

We wish to thank Leanne Pobjoy for the translation of the manuscript and PD Dr. Anne F Mannion, PhD, for her advice.

\section{References}

I. Dettmer N and Chrostek M: Gedanken zur Dokumentation bei der generalisierten Tendomyopathie (GTM). In Generalisierte Tendomyopathie (Fibromyalgie) Edited by: Müller W. Darmstadt Steinkopff; 1991:63-70.

2. Buskila D and Neumann L: Fibromyalgia syndrome (FM) and nonarticular tenderness in relatives of patients with FM. J Rheumatol 1997, 24:94I-4.

3. Jacobsson L, Lindgärde F and Manthorpe R: The commonest rheumatic complaints of over six weeks' duration in a twelvemonth period in a defined Swedish population. Scand I Rheumatol 1979, 18:353-60.

4. Raspe $\mathrm{HH}$ and Schochat T: Epidemiology of the Fibromyalgia Syndrome: definition, occurence, consequences, risk factors. Z Rheumatol 1997, 56:359-60.

5. Müller W: Der Verlauf der primären generalisierten Tendomyopathie (GTM). IN Generalisierte Tendomyopathie (Fibromyalgie) Edited by: Müller W. Darmstadt Steinkopff; 1991:29-43.

6. Bruppacher R and Geiger M: Epidemiologie und Kosten der generalisiertenTendomyopathie (GTM). In Generalisierte Tendomyopathie (Fibromyalgie) Edited by: Müller W. Darmstadt Steinkopff; |99|:57-62.

7. Pedroni G and Zweifel P: Die sozialen Kosten von Rheuma in der Schweiz. Studien zur Gesundheitsökonomie. Basel Pharmainformation 1986: $\mathrm{Nr} 9$.

8. Edwards $\mathrm{O}$ : Maladies rhumatismales en Suisse: quelques aspects économiques. Bern Peter Lang 198I.

9. Wolfe F, Smythe HA, Yunus MB, Bennett RM, Bombardier C, Goldenberg DL, Tugwell P, Campbell SM, Abeles M, Clark P, Fam AG, Farber SJ, Flechtner IJ, Franklin CM, Gatter RA, Hamaty D, Lessard J, Lichtbroun AS, Masi AT, McCain GA, Reynolds WJ, Romano TJ, Russell IJ and Sheon RP: The American College of Rheumatology 1990 Criteria for the Classification of Fibromyalgia. Report ofthe Multicenter Criteria Committee. Arthritis Rheum 1990, 33:160-72. 
10. Millea PJ and Holloway RL: Treating fibromyalgia. Am Fam Physician 2000, 62:1575-82.

II. Lindell L, Bergman S, Petersson IF, Jacobsson LT and Herrstrom P: Prevalence of fibromyalgia and chronic widespread pain. Scand J Prim Health Care 2000, 18: 149-53.

Publish with Bio Med Central and every scientist can read your work free of charge

"BioMed Central will be the most significant development for disseminating the results of biomedical research in our lifetime. " Sir Paul Nurse, Cancer Research UK

Your research papers will be:

- available free of charge to the entire biomedical community

- peer reviewed and published immediately upon acceptance

- cited in PubMed and archived on PubMed Central

- yours - you keep the copyright

Submit your manuscript here:

http://www.biomedcentral.com/info/publishing_adv.asp 